\title{
The establishment and analysis of the prosperity indexes for China's power market*
}

\author{
Bo Zeng, Li-Juan Qin, Xu Yan, Xi-Qiao Lin, Shuai Han and Li-Ke Gao \\ Electric Power Research Institute of Guangxi Power Grid Co., Ltd. \\ Nanning, Guangxi, China \\ ${ }^{\dagger}$ E-mail:qin_lj.sy@gx.csg.cn,594842366@qq.com
}

\begin{abstract}
As the pillar industry of the national economy, electric power has important influence on promoting the development of national macroeconomic. Along with the issuance of "No.9 Document" in 2015, China's power industry reform has entered a critical period. Based on the prosperity indexes analysis and forecast the development trend of power industry has important significance on the China's power industry reform. This paper starts with the indexes selection considering short-term, long-term and no market factors. The analysis of composite index has shown that the prosperity index of China's power market is above 100 from 2001 to 2014 and it's between 95 100 on the first half of 2015.At the same time, the regression correction has been carried out to enhance the accuracy of the prosperity index to reflect the development trend of electric power and the electricity market is in the downward phase of a new mild round of economic fluctuations. In the end, the paper puts forward that the reform of power industry in our country should be gradual, at the same time we should pay more attention to the establishment of power market mechanism, and maintain the continuity of policy and other rationalization proposals.
\end{abstract}

Keywords: Power Industry; Power Industry Reform; Prosperity Index; Composite Index.

\section{Introduction}

Power industry is of high degree industrial relevance, the development of which has a strongly stimulating and promoting effect on the upstream supply enterprises and downstream high energy consumption enterprises, as well as the economic structure and development changes of the district[1]. However, China's current power system has seriously hampered the development of national economy[2], power market reform is imperative. Nevertheless, throughout the world power market reform process, the reform are not finished overnight, but step by step with the development of economy, technology, environment[3], and the key to the periodic success of the national power market

\footnotetext{
* This work is supported by science and technology project of Guangxi Power Grid Co., Ltd (GX2014-2-0019)
} 
reform is making adaptive decisions along with different development stages. So that means the process of power market-oriented reform will also be a decisionmaking process which is phased and gradually adapted to the development of realistic economic development with industry's fair competition[4]. Therefore, for the development of the reform of the decision-making stage, predicting accurately the trend of power industry and the periodic fluctuation is critical. The analysis of the power market prosperity index will provide references for the formulation of government decision-making.

Prosperity index, also known as the boom, through summarizing the indexes reflecting economic fluctuations, reflects the status of the economic fluctuation cycle and future trends comprehensively[5-6]. Market prosperity has the repetitive, fluctuated and cumulative characteristics. The fluctuations of different industries contain certain sequence as well as transitivity, thereby affecting the entire national economy[7].It is possible to analyze economic trends in the overall operation by setting the scientific prosperity index with statistical rules. Prosperity index, since the first time used in the German Economic Research Institute has 70 years of history. China's research of using prosperity index to forecast economic cycle fluctuations is later, only twenty years[8].In 2009, Gao Tiemei, a famous scholar studied China's economic prosperity fluctuation in investment, consumption, foreign trade and other aspects as well as energy, real estate, manufacturing, services and other sectors[9]; In 2012, Liu Chang, Li Ying considering the law and characteristics of the power industry, by constructing the power industry prosperity index analyze the China's power industry running trends[10];This paper further proposes the prosperity changing sensitive indexes of various sectors selected from the short-term, long-term as well as non-market factors to reflect the impact of different sectors on the economy of power prosperity, further reflecting the power overall planning.

First, this paper selects a series of relevant economic indexes guiding economic cycle according to short-term market factors, long-term market factors as well as the non-market factors; Second, it uses time for screening economic indexes, determining benchmarking indexes and constituting leading indexes consistent indexes and lagging indexes; Finally, it draws up the composite indexes and monitor fluctuations in the economic cycle of the power industry with the composite indexes.

\section{Analysis Methods Suitable for the Power Market Prosperity Indexes}

At this stage, China's power market reform, during the startup period will promote electricity sells side market and Incremental distribution market 
orderly in the institutional framework of "release two regulate the middle", and will gradually form the power market competition of "multi-buyer -multi-seller". In the critical period of the power system reform, it is necessary to strengthen the power overall planning in order to ensure stable and healthy development of the power industry. Therefore, the power market prosperity indexes should be able to fully reflect power market prosperity situation under the influence of upstream industries, downstream industries and "generation- transmissiondistribution-sale" of power industry. It is of vital importance to consider the influence factors of the power industry, upstream and downstream industries in the view of all aspects and the whole system for creating suitable China's power market prosperity indexes.

\subsection{Selection process of power market prosperity indexes}

The economic development of power market and other sectors are interrelated and mutual restraint. In order to reflect the power industry overall planning, selecting power market prosperity indexes needs to consider the relevance of multiple factors in the power industry, upstream and downstream industries. In view of this, first select the 35 indexes representing China's power industry, up streamed downstream industry, short-term market factors, the long-term market factors and non-market factors; Second, make the index data consistent and dimensionless initially, while exclude the high correlation indexes with the correlation analysis between indexes[11];Finally, divide the selected indexes into leading indexes, consistent indexes and lagging indexes using the correlation coefficient between the time series, while the power market prosperity indexes selection process is shown in Figure 1.

Finally, as shown in Table 1, establish the power market prosperity index system with 10 indexes obtained by screening.

\subsection{Calculation of index weights}

This paper adopts the product root method to determine the index weights.

First, obtain comparative judge matrix between the $k$ indexes based on expert opinions is $A$ :

$$
A=\left[\begin{array}{cccc}
a_{11} & a_{12} & \cdots & a_{1 k} \\
a_{21} & a_{21} & \cdots & a_{2 k} \\
\vdots & \vdots & \vdots & \vdots \\
a_{k 1} & a_{k 1} & \cdots & a_{k k}
\end{array}\right],\left\{\begin{array}{c}
a_{i j}>0 \\
a_{i i}=1(i=1,2, \cdots, k) \\
a_{j i}=1 / a_{i j}(i, j=1,2, \cdots, k)
\end{array}\right.
$$

Where, $a_{i j}$ represents the relative weight of index $i$ to the index $j$.

Multiply multiplication the $m$ in the line elements and open $m$-th power, namely the geometric mean ${ }^{b_{i j}}$ ofall row elements: 


$$
b_{i}=\left(\prod_{j=1}^{m} a_{i j}\right)^{1 / m}
$$

Then normalize ${ }^{b_{i j}}$ namely the weight of index $^{i}$ :

$$
W_{i}=b_{i} / \sum_{i=1}^{k} b_{i}
$$

\subsection{The preparation of power market prosperity indexes}

Currently, there are two common international prosperity index method, one is diffusion index (Diffusion Index, DI), which can effectively analyze economic fluctuations and economic fluctuations turning point occurred; The other is the Composite Index (Composite Index, CI), not only represents a turning point in the economic fluctuation, but also expresses the degree of fluctuation[12]. Composite Index provide more detailed information compared to diffusion index, therefore, this paper will use the composite index method to analyze the power market prosperity indexes.

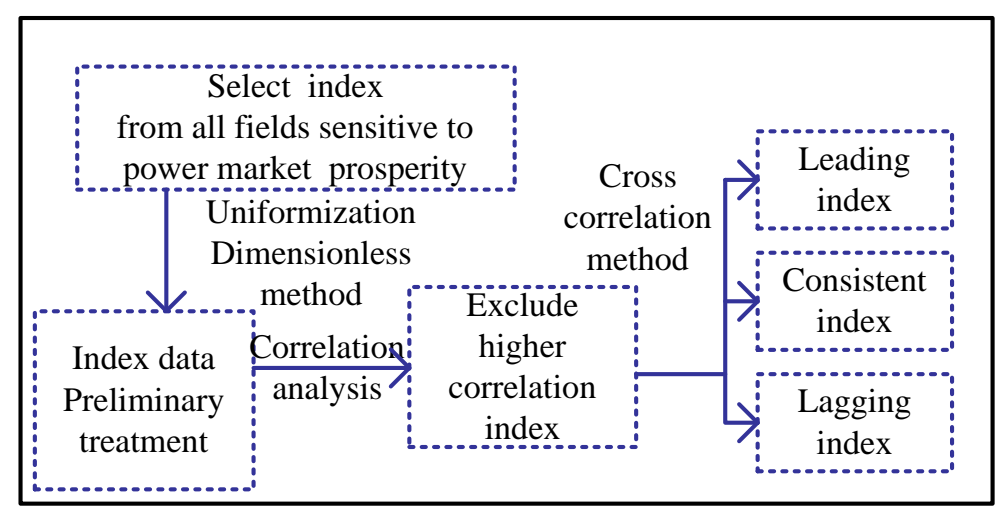

Fig. 1 The selection process of prosperity indexes for electricity market 
Table1. Prosperity indexes system for China's power market

\begin{tabular}{|c|c|c|c|}
\hline types & Index name & $\begin{array}{c}\text { Cross } \\
\text { correlation } \\
\text { coefficient }\end{array}$ & $\begin{array}{l}\text { Months } \\
\text { delayed }\end{array}$ \\
\hline \multirow[t]{4}{*}{$\begin{array}{l}\text { Leading } \\
\text { index }\end{array}$} & $\begin{array}{l}\text { Industrial energy } \\
\text { consumption share }\end{array}$ & 0.78 & -2 \\
\hline & $\begin{array}{l}\text { Fixed assets investment } \\
\text { of power industry }\end{array}$ & 0.67 & -3 \\
\hline & $\begin{array}{c}\text { Cement manufacturing } \\
\text { output }\end{array}$ & 0.88 & -4 \\
\hline & Steel industry output & 0.64 & -3 \\
\hline \multirow{4}{*}{$\begin{array}{l}\text { Consistent } \\
\text { index }\end{array}$} & Generating capacity & 1 & 0 \\
\hline & $\begin{array}{c}\text { Total taxes of power } \\
\text { industry }\end{array}$ & 0.93 & 1 \\
\hline & $\begin{array}{l}\text { Power consumption } \\
\text { elasticity coefficient }\end{array}$ & 0.85 & 1 \\
\hline & GDP per capita & 0.80 & -1 \\
\hline \multirow[t]{2}{*}{$\begin{array}{l}\text { Lagging } \\
\text { index }\end{array}$} & $\begin{array}{l}\text { Coal mining industry } \\
\text { revenue }\end{array}$ & 0.71 & 4 \\
\hline & $\begin{array}{l}\text { Thermal power } \\
\text { generation amount share }\end{array}$ & 0.80 & 3 \\
\hline
\end{tabular}

Calculating the composite index is required to first calculate the changing rate of the individual indexes:

$$
\begin{gathered}
C_{i t}=\frac{100\left(d_{i t}-d_{i t-1}\right)}{\left(d_{i t}+d_{i t-1}\right) / 2}=200 \times \frac{\left(d_{i t}-d_{i t-1}\right)}{d_{i t}+d_{i t-1}} \\
A_{i}=\sum_{t=2}^{N} \frac{\left|C_{i t}\right|}{N-1} \\
S_{i t}=C_{i t} / A_{i}
\end{gathered}
$$

Where, $b_{i j}$ represents the changing rateof single index $i$ in period $t, d_{i t}$ represents actual value of single index $i$ in period $t, A_{i}$ represents the average value of single index $i$ symmetry changing rate of time series, $s_{i t}$ represents the standardization value of symmetry changing rate of single index ${ }_{i}$ in $_{\text {period }}, N$ represents the number of periods.

Symmetry changing rate of comprehensive multi-index:

$$
R_{t}=\left(\sum_{i=1}^{k} S_{i t} W_{i}\right) /\left(\sum_{i=1}^{k} W_{i}\right)
$$


Where, $R_{t}$ represents average symmetry changing rate of comprehensive multi-index; ${ }_{k}$ is the number of indexes; ${ }_{W_{i}}$ represents the weight of index $i$.

Calculate normalization factor $F$ :

$$
F=\left[\left(\sum_{t=2}^{N}\left|R_{t}\right|\right) /(N-1)\right] /\left[\left(\sum_{t=2}^{N}\left|P_{t}\right|_{i}\right) /(N-1)\right]
$$

Where, $R_{t}$ represents average symmetry changing rate of comprehensive multi-index of leading indexes or lagging indexes in period ${ }_{t} ; P_{t}$ represents average symmetry changing rate of comprehensive multi-index of consistent indexes in $\operatorname{period}_{t}$.

Calculate the average changing rate as coincident index standardization:

$$
V_{t}=R_{t} / F
$$

Where, ${ }^{{ }^{t}}$ represents the average coincident changing rate standardization.

Calculate the initial composite index of power market.

$$
I_{t}=\frac{I_{t-1}\left(200+V_{t}\right)}{200-V_{t}}, \quad t=2,3, \cdots, m
$$

Calculate the final composite index of power market.

$$
C I_{t}=\left(I_{t} / I_{0}\right) \times 100 \%
$$

Where, ${ }^{C I}{ }_{t}$ represents composite index; ${ }^{I}$ represents the average value of the basic years selected.

\section{China's Power Market Prosperity Index Calculation Results and Discussion}

Select annual data of 2001-2014 and the first half statistics of 2015, calculate China's power market prosperity index, according to the calculation method of the composite index, regarding the 2000 as the basic year, shown in Table 2. 
Table 2 The calculation results of prosperity indexes for China's power market

\begin{tabular}{cccc}
\hline year & Leading index & Consistent index & Lagging index \\
\hline 2001 & 104.4 & 101.5 & 102.1 \\
2002 & 108.9 & 104.3 & 102.4 \\
2003 & 107.4 & 107.1 & 110.2 \\
2004 & 104.3 & 108.4 & 111.4 \\
2005 & 120.5 & 104.3 & 118.7 \\
2006 & 122.7 & 111.2 & 113.1 \\
2007 & 116.4 & 114.5 & 117.1 \\
2008 & 103.4 & 108.1 & 119.6 \\
2009 & 98.3 & 103.5 & 111.2 \\
2010 & 102.1 & 101.3 & 108.9 \\
2011 & 102.5 & 103.8 & 101.1 \\
2012 & 103.3 & 103.2 & 101.9 \\
2013 & 101.6 & 103.5 & 102.4 \\
2014 & 103.3 & 101.7 & 101.6 \\
2015 & 99.1 & 101.2 & 99.7 \\
\hline
\end{tabular}

The power capacity ratio is the ratio of the installed capacity in this year to that of last year, on behalf of the generating capacity demand of power market in a certain period, reflecting the judgments of power market for the form of the current power supply market. Therefore, the power capacity ratio can reflect the prosperity situation of the power market to some extent. Draw the power market prosperity data result and the ratio of the actual power installed capacity together in China's power market prosperity figure, shown in Figure 2.

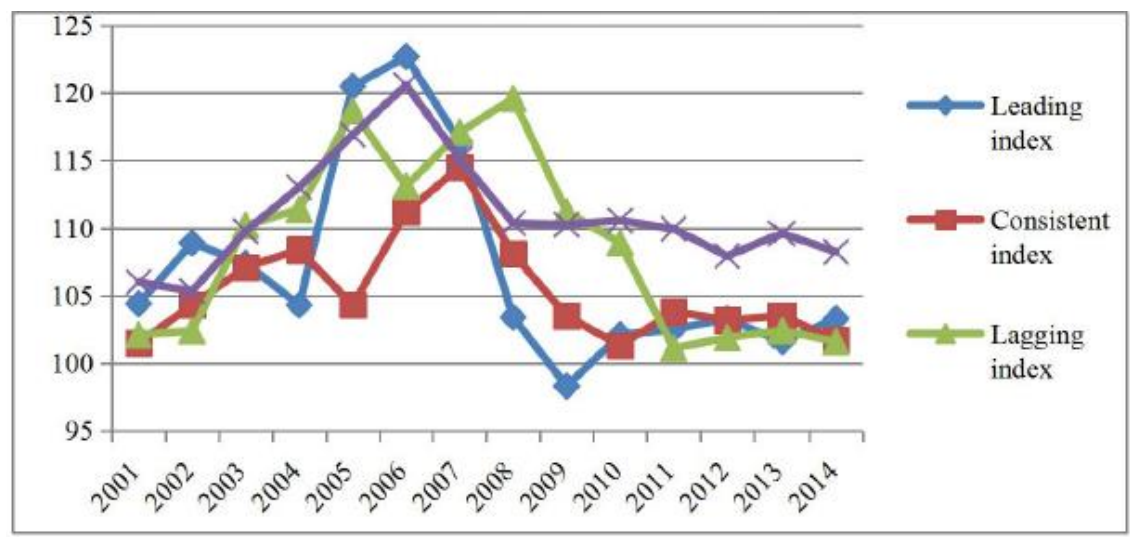

Fig. 2 The prosperity indexes for China's power market

As it is seen from the figure, the coupling degree of the consistent composite index, the leading composite index and lagging composite index are relatively high, occurred three times; The leading average period of peak and 
valley values of leading composite index compared with consistent composite index is about one year, compared with lagging composite index is about 2 years; There are two peaks of China's power market consistent composite index respectively in 2004 and 2007,whilefrom 2001 to 2005 it occurred first fluctuation and from 2005 to 2010 occurred the second fluctuation, and China's power market in the current stage is in the third fluctuations beginning in 2010.However, by comparing the figure, there is no intuitive relevance of the power market prosperity with the installed capacity ratio, therefore to enhance the forecasting accuracy of prosperity index to the power market trend, it is necessary to conduct further amendments to the power market prosperity.

The correlation analysis of power market prosperity indexes and the ratio of the installed capacity are shown in Table 3.

Table 3 The Correlation Coefficient between the prosperity indexes and the ratio of the installed capacity

\begin{tabular}{cccc}
\hline $\begin{array}{c}\text { Correlation } \\
\text { coefficient }\end{array}$ & Leading index & Consistent index & Lagging index \\
\hline $\begin{array}{c}\text { Installed } \\
\text { capacity ratio }\end{array}$ & 0.764 & 0.656 & 0.694 \\
\hline
\end{tabular}

From the results of the correlation coefficient in Table 3, there is a good correlation between the power market prosperity and the ratio of installed capacity. Next step, conduct regression analysis regarding power market prosperity index as independent variable, the ratio of installed capacity as dependent variable obtaining the corrected prosperity index shown in Figure 3. It can be seen from the Figure 3 that the fitting situation of the corrected power market prosperity index and the ratio of installed capacity has greatly improved than before, while the power market prosperity index is more intuitive, reasonable, and better reflect the power market prosperity extent and trends.

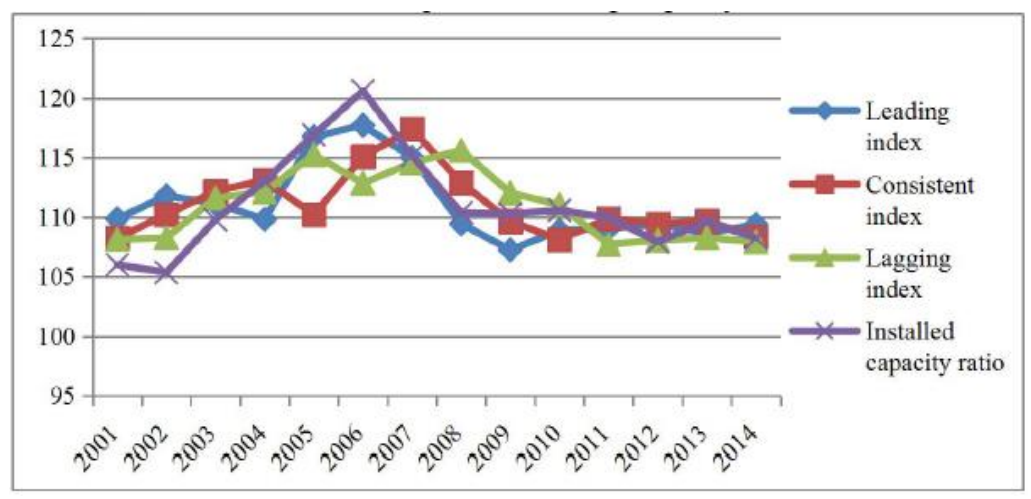

Fig. 3 The Modified electricity market prosperity index 
Combining the reality of China's power market prosperity, China has successful accession to the WTO in 2002, and has implemented a proactive fiscal policy, developed industrial parks, promoted large-scale industrial projects, with the rapid growth of total foreign investment, providing China's power industry development a new round of growth. During this period, it has appeared the rapid development of the power supply market, as well as a serious power shortage, power market expansion achieving the peak of this increasing round in 2004. Since the contradiction between power supply and demand, China has constructed power plant projects around the country, by 2006 power supply and demand achieving overall balance, and the tight power supply situation has been significantly eased, but there are still some areas in the state of tension.

Since 2004 the power price increased while some power plants operated with deficit, the government has implemented coal and power price cooperative mechanismto solve the problem which has brought the peak of the second round of power expansion in 2007. Affected by the 2008 global financial crisis, China has proposed the idea of establishing environment-friendly society and gradually phased out high energy-consuming enterprises, making the power market prosperity index decline sharply.

In recent years, China's economic growth has entered into new normal state, gradually changed "extensive" mode of development. The power market prosperity index has entered a new period of volatility, which appears more gently and is in the economic downturn stage. From the past two rising economic power situation, the policy has played a key role, thereby as long as the appropriate policy mechanisms are in line with the development stage, the recovery of the power market will be just around the corner.

Based on the above forecasting analysis, there are following recommendations. First, China's electric power system reform should be gradual, strengthening technological innovation, promoting distributed generation and renewable energy development, entering science and technology-saving way and promoting industrial upgrading; Second, focus on improve the power market mechanism, open power selling market as well as incremental distribution market, revert commercial product attributes of power, give market mechanism full play to the role of optimizing allocation resources; Finally keep policy mechanisms in the state of continuity and stability to ensure policy weaken the fluctuations of industry, promote the coordinated development of macro economy. 


\section{Conclusion}

The importance of the power industry for the national economy as well as its complexity and highly relevance with multi-industry determine that it is necessary to through the scientific method of statistical theory, accurate data and precise operation for predicting the industry development to reduce future power market development decision losses caused by uncertainty. This paper through power market prosperity index analysis, provides the evidence that China's power market economic level is in flat period in the new normal state, and the role of power market reform policy at this time will be particularly prominent. It is significant to seize the important opportunity ofpower market reform, clear energy saving, emission reduction, carbon reduction and technological innovation, market opening development direction to improve quality of power economy growth and social benefits.

\section{References}

1. Liu Chang, Gao Tiemei. Characteristics of Electricity Industry Cycle Fluctuation and Influential Factors of Electricity Demand Based on Business Analysis and the Error Correction Model[J]. Resources Science, 2011, 01: 169-177.

2. Liu Chang. Analysis and Outlook of Situation and Changes of structure of China Power Industry in 2013[J]. Science \& Technology for Development, 2013, 06: 91-95.

3. Pim Vugteveen, Etienne Rouwette, Hendrik Stouten, etc. Developing social-ecological system indicators using group model building[J]. Ocean \& Coastal Management,2015(109):29-39.

4. Huang Xiaobo, Cao Chunman, Zhu Peng. Research on Enterprise Prosperity Index Based on Accounting Information: Based on the Data of Chinese Listed Companies From 2007 to 2012[J]. Journal of Nanjing Audit University, 2013, 05: 61-66.

5. Tong-

SengQuah,SrinivasanB.ImprovingaccuracyofneuralPredictionbymarketseg mentation.ProceedingsoftheInternationalConferenceonArtificial Intelligence[C]. 2000, 2(4): 935-93.

6. Liu Dian. Research on The Economic Co-movement between ChinaandOtherMainEconomiesEmpiricalAnalysisBasedonCompositeLeadi ngIndex[D]. East China Normal University, 2011.

7. Ding Haijing. The Research of Chinese Electric Power Industry's Booming Index and Fluctuation[D].Anhui University, 2014. 
8. Yan Shaowu. The analysis and forecasting of macroeconomic climate based on generalized dynamic factor mode[D]. Dongbei University of Finance and Economics, 2013.

9. Gao Tiemei, Wang Jinming, Chen Fei. An empirical analysis of the fluctuation of economic growth cycle in China's transition period[J]. Research on Financial and Economic Issues, 2009, 01: 22-29.

10. Liu Chang, Li Ying. Analysis of Situation and Structure Changes of China Power Industry in 2012[J]. Science \& Technology for Development, 2012,09: 78-83.

11. Ren Zeping, Chen Changsheng. Economic Cycle Fluctuation and Changes in Industry Prosperity: Causality, Transmission Mechanism and Policy Implication[J]. Economic Perspectives, 2012, 01: 19-27.

12. Gao Tiemei, Kong Xianli, Wang Jinming. The Research of International Economic Sentiment Analysis[J]. The Journal of Quantitative \& Technical Economics, 2003, 11: 158-160+163. 